\title{
Aid Tying and Donor Fragmentation
}

\author{
Stephen Knack ${ }^{* 1}$ and Lodewijk Smets ${ }^{\dagger 2}$ \\ ${ }^{1}$ World Bank, Washington D.C. \\ ${ }^{2}$ Insitute of Development Policy and Management, University of Antwerp, Belgium
}

*1818 H St. NW, Washington DC 20433, phone: 202-458-9712, fax: 202-522-1154, email: s.knack@worldbank.org

${ }^{\dagger}$ Prinsstraat 13, 2000 Antwerp, email: lodewijk.smets@ua.ac.be 


\begin{abstract}
This study analyzes theoretically and empirically the impact of aid fragmentation on donors' decisions to tie their development aid to purchases from contractors based in their own countries. Building on collective action theory, it argues that a donor with a larger share of the aid market in a country has stronger incentives to maximize the development impact of its aid, by tying less of it. Empirical tests strongly and consistently support the prediction that higher donor aid shares will be associated with less aid tying. This finding is robust to recipient controls, donor fixed effects and instrumental variables estimation. Furthermore, it contradicts other studies suggesting that when a small number of donors dominate the aid market in a country, they may exploit their monopoly power by tying more of their aid.
\end{abstract}

Keywords: aid, development assistance, collective action, corruption 


\section{ACKNOWLEDGEMENT}

We would like to thank William Nicol, Adam Wagstaff and three anonymous referees for useful comments and suggestions. 


\section{INTRODUCTION}

A consensus in the international aid community holds that tying aid to purchases from the donor country reduces its effectiveness. More recently a consensus has also emerged on the importance of reducing aid fragmentation and the transactions costs it imposes on recipient countries. This study analyzes theoretically and empirically the relationship between aid fragmentation and aid tying. Borrowing from collective action theory, we argue there are important benefits from concentrating aid among fewer donors, in addition to the reduction in transactions costs that are commonly noted. Namely, the responsibility for development outcomes is less diffused, so donors are less likely to indulge in practices that undermine aid's effectiveness. A donor with a larger share of the aid market in a country has a stronger incentive to maximize the development impact of its aid instead of pursuing commercial or other non-development objectives. Thus, more concentrated aid should be associated with less tying of aid.

Our empirical tests strongly and consistently support this prediction. Untying aid and reducing fragmentation turn out to be complementary objectives. Higher donor aid shares, and lower values on fragmentation indexes, are associated with lower rates of aid tying. These findings are robust to recipient controls, donor fixed effects, instrumental variables estimation, and to analyzing data from different years.

When recipient countries are grouped by their scores on corruption perception indexes, donors with higher aid shares are generally found to tie significantly less aid only in the less-corrupt subsample. This finding is consistent with the argument that aid tying can be an efficient response by donors where losses from corruption may rival or exceed losses from tying aid.

Where aid tying is more costly, as proxied by donor country size and income, it is less prevalent.

Furthermore, we find aid tying is lower in the Least Developed Countries, consistent with the OECD-DAC's recommendation to its members on aid tying.

Our results add to the nascent literature on the determinants of aid tying (Aryeetey, Osei, \& Quartey, 2003; Clay, Geddes, \& Natali, 2009). They also have implications for an alternative perspective on aid fragmentation. Some observers caution that reducing aid fragmentation can reduce the bargaining power of a recipient country government relative to that of its remaining donors. If reducing the number of donors implies they have more monopoly power, donors may exploit this increased power by tying more of their aid to purchases from contractors based in their own countries. Our findings suggest such concerns are unwarranted. Conceivably, donors could exercise any monopoly power in other ways, such as imposing extraneous conditionality, or 
investing less effort in designing good projects or in a policy dialogue. In contrast to the case of aid tying, however, reasonably comprehensive data on these other aid practices are not available for most donors.

The remainder of the paper is organized as follows. Section 2 reviews the relevant literature on aid tying and on donor fragmentation, from aid scholars and aid organizations (most notably the OECD-DAC). In section 3 we present a simple model of donor behavior, similar to common pool resource models of voluntary collective action, that predicts larger aid shares (and lower fragmentation index values) will be associated with less aid tying. The model also generates the trivial but testable prediction that aid tying will be inversely related to its costs. A straightforward extension of the model generate the prediction that donor aid shares will be more weakly (or even positively) related to aid tying if corruption is a sufficiently severe problem in recipient governments. The data are described and empirical findings presented in section 4, including results from both OLS and IV estimation and various robustness tests. Section 5 concludes.

\section{BACKGROUND}

There is little agreement on aid's development impact, and on how to improve its effectiveness. Although empirical evidence remains relatively scarce, a consensus has emerged in the development aid community regarding certain donor behaviors, as reflected in the 2005 Paris Declaration on Aid Effectiveness. Among other actions, this agreement urges donors to reduce aid fragmentation and to untie more of their aid. The practice of tying aid - providing it conditional on using it to purchase goods and services from suppliers based in the donor country - has been estimated to increase costs by $5 \%$ to $30 \%$, or even more for food (Aryeetey et al., 2003; Clay et al., 2009; Jepma, 1991). The OECD's Development Assistance Committee (DAC) therefore issued a recommendation to its members in 2001 to untie aid to the Least Developed Countries (LDCs) to the largest extent possible, but exempting food aid, technical assistance, and aid channeled through NGOs instead of recipient governments ${ }^{1}$. Aid untying is monitored under the Millennium Development Goals, as one of many indicators under the 8th goal of developing a global partnership for development. Tying aid not only reduces its value to the recipient, but is considered to be inconsistent with the Paris Declaration (PD) principles of country ownership and alignment with country priorities and systems. The share of aid that is untied is thus included as one of the 12 PD Indicators for improved aid effectiveness (OECD, 2011). Untied aid as a share of total aid from the DAC donors appears to have increased since the recommendation was issued, although figures are not fully comparable over time, as reporting standards have also improved (Clay et 
al., 2009). Untying aid is one of many numerical indicators of donor performance in comparative assessments produced by Birdsall, Kharas, and Perakis (2011), Knack, Rogers, and Eubank (2011) and Easterly and Williamson (2011). Donors vary with respect to how much of their aid is untied, for aid that is covered by the recommendation and for exempted categories. Moreover, a given donor may vary with respect to how much of its aid is tied in different recipient countries. A donor's share of the aid market in each of its recipients is one possible determinant of the extent of its aid tying.

There are potentially trade-offs or complementarities between untying aid and another objective in the Paris Declaration, namely reducing aid fragmentation. Recipient countries are faced with an increasing number of donors engaged in delivering development assistance. For instance, in 1960 a developing country received aid from less than two donors on average, while in 2006 the average number of donors per recipient had risen to more than twenty eight (Frot \& Santiso, 2008). Several studies, including Acharya, de Lima, and Moore (2006) and World Bank (2003, Ch. 7) argue that this proliferation of donors imposes high transaction costs on recipient governments, thereby reducing the value of aid. Anderson (2011) shows that fragmenting a donor's aid across many recipients is associated with higher reported administrative costs by the donor. Knack and Rahman (2007) show that where aid is more fragmented among donors, the quality of government bureaucracy in the recipient country deteriorates more. They argue that when donors each have only a small share of the aid market, they tend to focus more narrowly on delivering successful projects, even at the risk of undermining government capacity by hiring away the most talented public managers. Kimura, Sawada, and Mori (2007) claim that donor proliferation hinders economic growth, and Djankov, Montalvo, and Reynal-Querol (2009) refine this argument, presenting evidence that donor fragmentation reduces economic growth in part through increased corruption.

Concerns over the transactions costs incurred by recipients in dealing with so many donors are reflected in the donor harmonization provisions of the Paris Declaration. Several harmonization indicators, with specific targets, are included in the Paris Declaration Monitoring framework (OECD, 2011), although these do not call specifically for donors to concentrate their aid on fewer countries. The Accra Agenda for Action, issued at the Third High Level Forum on Aid Effectiveness in September 2008, asserts that the "effectiveness of aid is reduced when there are too many duplicating initiatives, especially at country and sector levels." It commits a broad range of aid providers to "reduce the fragmentation of aid by improving the complementarity of donors' efforts and the division of labor among donors, including through improved allocation of resources within 
sectors, within countries, and across countries." OECD (2009) suggests that donors re-allocate some of their aid from "non-significant" to "significant" relationships (those where aid is relatively small from both the donor's and recipient's standpoints).

Some observers, however, warn about harmful effects on recipients from excessive donor harmonization. Rogerson (2005) and Frot and Santiso (2009) note that a low Herfindahl index is interpreted as an indicator of healthy competition among firms in the economics of industrial organization literature, and argue that high aid fragmentation (measured by one minus the Herfindahl index) may similarly reflect more competition among donors, to the benefit of recipients. The DAC itself (OECD, 2011, Ch. 4) in describing the costs of fragmentation also acknowledges that a recipient may benefit from having a diversified set of funding sources and from working with numerous donor agencies with different areas of expertise. "In addition to the policy autonomy that might be forfeited" from dependence on one key donor, "the recipient would also likely face a riskier ODA environment" if subject to the foreign policy whims and changes in economic circumstances of a single large bilateral donor (Rowlands \& Ketcheson, 2002). A donor agency evaluation found that government officials in some countries (including Benin and Malawi) favored a single assistance strategy guiding all donors' activities in their countries, but other governments were not interested, "as they preferred to have options, which would be undermined if donors coordinated on a joint strategy" (IEG, 2011). In general, therefore, benefits to the recipient from this competition, diversity of ideas and more consistent flow of total funds should be balanced against the higher transactions costs of fragmentation (Rogerson, 2005). Gibson, Andersson, Ostrom, and Shivakumar (2005) and Frot and Santiso (2009) assert more specifically that donors with monopoly power in a country may exploit it by tying more of their aid. They do not provide empirical tests of this hypothesis, but if they are correct there is a tradeoff between two of the PD goals: progress toward an improved division of labor among donors will tend to slow progress on untying aid.

While the monopoly argument implies that aid fragmentation should reduce the incidence of aid tying, other views of donor-recipient interactions imply there should be no relationship. Easterly (2002) agrees that aid fragmentation imposes more transactions costs on recipients, but believes it does not materially affect the balance of power between a recipient and donor. Donors in a recipient country act as a de facto cartel, in Easterly's view, whether they are few or numerous. Munro (2005) is skeptical of claims regarding the benefits of concentrating a donor's aid on fewer countries and sectors, noting a dearth of systematic empirical evidence, but he is also skeptical that 
a typical donor can increase its leverage with a recipient government by increasing its share of the aid market in the country. This view of limited donor influence contrasts starkly to Easterly's, but both views suggest that a donor's ability to impose its will on a recipient government is unrelated to its share of the aid market in the country. Finally, aid markets may be highly contestable even in countries where we observe few donors operating in equilibrium. Recipients have been known to accept aid from certain donors while rejecting it from others they find less compatible for one reason or another. Donor leverage or monopoly power is difficult to measure, and available proxies such as fragmentation indexes or the number of donors are at best crude approximations. In empirical tests of the link between fragmentation and aid tying, therefore, a failure to reject the null could mean either (1) available measures of fragmentation are poor measures of monopoly power, or (2) donors do not exploit their monopoly power to tie more of their aid, or both.

Acharya et al. (2006) and Knack and Rahman (2007) offer a differing perspective, arguing that the degree of fragmentation may powerfully affect donor incentives to pursue development objectives. Building on collective action theory (Hardin, 1982; Olson, 1965, 1982), Knack and Rahman (2007) argue that higher aid shares give donors a more "encompassing interest" (Olson, 1982) in a country's development. Where numerous donors operate and each provides only a small part of development assistance, responsibility for development outcomes is diffused. "The more donors there are, the easier it is to assume or assert that the lack of development progress is someone else's fault" (Acharya et al., 2006). Any single donor has little reputational stake in the success or failure of the recipient's development program. This collective action problem is exacerbated if donors - as generally acknowledged in the literature - have multiple objectives. Bilateral aid programs are not designed solely to pursue development objectives (public goods) but also to pursue commercial, security or other objectives ("private" goods, in the sense that they have no value to the recipient or to other donors). As illustrated by a simple model below, donors may trade off these objectives differently, and a given donor might make different trade-offs in different countries.

\section{A SIMPLE FORMALIZATION}

Assume there are $n \geq 1$ donors present in a recipient country. Donors' total utility from the development benefits of each unit of untied aid and tied aid are, respectively, $Y$ and $Y-c$, where $c>0$ and represents the costs (i.e. reduction in development benefits) of a donor's decision to tie aid. We consider the benefits of development as a rival but non-excludable public good for which each donor gets credit, in terms of agency or national prestige, in proportion to the share of aid 
it contributes. Each donor also receives a private benefit $X$ from each unit of tied aid it provides, and zero benefits from each unit of tied aid other donors provide. We assume that $X<Y$. Donor $i$ 's utility can therefore be written as:

$$
u_{i}\left(a_{i, T}\right)=S_{i}\left(\sum_{j=1}^{n} a_{j, T}\left(Y-c_{j}\right)+\sum_{j=1}^{n}\left(a_{j}-a_{j, T}\right) Y\right)+a_{i, T} X
$$

where $a_{i, T}$ is the amount of tied aid donor $i$ provides, $S_{i}=a_{i} / \sum_{j=1}^{n} a_{j}$ represents the share of aid in the country provided by donor $i, a_{j, T}$ is the amount of tied aid donor $j$ disburses, and $a_{j}$ is the total aid donor $j$ contributes.

Proposition 1. If $i$ is the only donor present in the recipient country, it does not tie its aid.

Proof. When a single donor provides all of the aid in the recipient country, its utility function reduces to:

$$
\left.u_{M}\left(a_{M, T}\right)=a_{M, T}\left(Y-c_{M}\right)+a_{M}-a_{M, T}\right) Y+a_{M, T} X
$$

The monopoly donor will tie aid if and only if $X-c>Y$, but by assumption $X<Y$. It follows that no aid will be tied.

Proposition 2. In the general case where multiple donors are present in the recipient country, aid tying will be inversely related to the donor's aid share and tying costs (i.e. development losses from tying aid).

Proof. When a donor has only part of the aid market, equation 3.1 can be rewritten as

$$
u_{i}\left(a_{i, T}\right)=B_{i}+a_{i, T} X-S_{i} a_{i, T} c_{i}
$$

by collecting terms independent of donor $i$ 's aid tying decision, where $B_{i}=S_{i}\left(\sum_{j \neq i}^{n} a_{j, T}(Y-\right.$ $\left.\left.c_{j}\right)\right)+S_{i}\left(\sum_{j \neq i}^{n}\left(a_{j}-a_{j, T}\right) Y\right)+S_{i} Y a_{i}$. Consequently, donor $i$ will untie its aid if and only if

$$
X<S_{i} c_{i}
$$

Equivalently, a donor will tie its aid if and only if its benefits from doing so, $X$, exceed its share of the development losses, $S_{i} c$. Thus, donors with higher tying costs and higher aid shares are less likely to tie their aid ${ }^{2}$. In deciding whether to tie aid, donor $i$ weighs its share of the costs of aid 
tying in forgone development benefits against its "private" benefits from aid tying. When it is the only donor it fully internalizes the costs, which exceed its benefits. More generally, it internalizes only $S_{i}$ of the cost and other donors collectively bear $1-S_{i}$ of the costs associated with donor $i$ 's tying of aid in the country. The assumption that benefits to donors are (at least partially) rival is crucial to this result. If a donor values all development outcomes equally regardless of whether it contributed any aid or not, it may still tie aid, but the aid tying decision would be independent of its share of aid provided.

The DAC's position is that tying aid increases costs, and benefits only special interests in donor countries. By assuming that $X<c$, we can incorporate in the model this assumption that aid tying is inefficient from the perspective of producing development benefits. Then the model generates not only positive but also normative implications regarding the optimal number of donors. Specifically, higher donor shares (associated with fewer donors) reduce aid tying, enhancing efficiency. Reality is likely more complex than reflected by the DAC's position, however. First, for small contracts the added search costs of a fully competitive procurement process may sometimes exceed any potential cost savings. Second, tying aid may strengthen political support for larger aid budgets in some donor countries, and the additional aid flows may fully compensate for the cost inefficiencies associated with tying aid. There is little if any data or evidence bearing on these two arguments. However, a third argument on efficient aid tying is more empirically tractable. Amegashie, Quattara, and Strobl (2007) raise the possibility that tying aid could prevent it from being embezzled by public officials. The implication is that where corruption is sufficiently severe, the development benefits from tied aid could exceed those from untied aid. Then, the losses of tying aid must be balanced against losses from graft. Accordingly, we extend the model below to incorporate corruption.

Proposition 3. When recipients differ with respect to the incidence of graft, donors are more likely to tie their aid in countries where losses from graft for untied aid are greater.

Proof. Where there are potential losses in development benefits of aid from graft, the donor's benefits from a unit of tied aid are still $X+Y-c_{i} S_{i}$, but now the benefits of untied aid are $Y-g S_{i}$ instead of $Y$. Donors tie aid if

$$
X>S_{i}\left(c_{i}-g\right)
$$


Where $g>c_{i}$, tying is efficient: net development losses are reduced when aid is tied to prevent aid from being embezzled. Empirically, we cannot determine how prevalent is this case, but we have no reason to question the implicit assumption in the DAC's untying campaign that it is relatively rare ${ }^{3}$. For a subset of the most graft-ridden recipient countries, however, it is plausible that $g$ could rival $c_{i}$ in magnitude. Note that in the case where tying is efficient, i.e. $g>c_{i}$, tying is more likely when $S_{i}$ is higher. Our indicators of tying costs and corruption are too crude to identify these cases in the data to test this hypothesis directly. However, we can test the prediction that in a subset of the more corrupt countries, the negative relationship between aid share and tying will be weaker in magnitude, and possibly even reversed in sign. Alternatively, the negative relationship between aid shares and aid tying may strengthen when the most corrupt recipient countries are dropped from the sample.

In another variation of the model, we assume that credit (or blame) for development outcomes is equally shared among all active donors in the recipient country, rather than in proportion to aid shares. While this assumption regarding donor motivation seems less plausible in general, some stylized facts appear to support it. One reason (among others) as to why small donors fragment their aid across many recipients may be the credit they receive out of proportion to their aid shares when they have at least a minimal presence in the country. The tendency of aid to flow to well-performing countries remarked on by some observers (Cassen, 1986) is also consistent with this assumption ${ }^{4}$. In this variant of the model a donor's utility function can be written as:

$$
u_{i}\left(a_{i, T}\right)=\frac{1}{n}\left(\sum_{j=1}^{n} a_{j, T}(Y-c)+\sum_{j=1}^{n}\left(a_{j}-a_{j, T}\right) Y\right)+a_{i, T} X
$$

with $n$ the number of donors present in the recipient country. This setup generates similar predictions: in the general case where multiple donors are active, a donor will untie its aid if and only if

$$
X<\frac{1}{n} c_{i}
$$

According to equation 3.6 aid tying is more likely to occur in recipient countries with many donors, leading to higher shares of tied aid, $\sum_{j=1}^{n} a_{j, T} / \sum_{j=1}^{n} a_{j}$, for those countries. In the next section we empirically test the predictions of the basic model and these two variations.

The model, and the empirical tests below, abstract somewhat from real-world complexity in treating donors as unitary actors. Some bilateral donors deliver aid through multiple agencies. Even where there is only one agency, whether aid is tied in a particular case can be a function of 
many idiosyncratic factors. Each aid project or program may involve a different combination of commercial interests, advocacy groups, politicians, and aid agency officials. If these idiosyncratic factors predominate in decision making, our empirical tests based on country-level indicators are unlikely to uncover any regularities in the data consistent with the model's predictions. Our working assumption, supported by results presented below, is that there are sufficient commonalities within a given donor's aid programs and large differences "on average" in aid tying and other behaviors across donors - that the unitary-actor assumption has some validity, despite abstracting somewhat from reality.

\section{EMPIRICAL TESTING}

Comparative statics of section 3 show that aid tying is inversely related to the donor's share of aid in a country, and that aid tying is more likely to occur in recipient countries with many donors. Below we first summarize the related empirical literature, then describe the models and data used for testing these predictions, and finally we present our empirical findings, including some robustness tests.

\section{(a) Previous empirical studies}

We have found only two previous empirical studies on the determinants of aid tying, and neither of them considers the possible impact of donor aid shares. Clay et al. (2009) analyze variation in aggregate aid tying rates for $22 \mathrm{DAC}$ bilateral donors for the year 2006. Tying rates are lower for donors that provide a larger share of their aid to LDCs and a lower share of their aid in the form of food assistance. Using donor aggregates as their unit of analysis, Clay et al. (2009) are unable to test the impact of recipient characteristics, or of factors that vary at the level of donor-recipient pairs, such as donor aid shares. Amegashie et al. (2007) uses recipient aggregates as the unit of analysis, so they also are unable to test variables measured at the donor-recipient level. They separately analyze tying of bilateral and multilateral aid, and fail to note that the EU is the only multilateral that ties its aid (its aid is all classified as partially tied). Their analysis of recipient-level determinants of multilateral aid tying is thus, in effect, an analysis of the EU's aid allocation decisions. For multilateral aid, Amegashie et al. (2007) find that well-governed countries have lower (partially) tied aid, i.e. EU aid. For bilateral aid, no significant relationship is found between tying and quality of governance. The analyses control for per capita income and population. Neither control variable is significant for multilateral aid, but bilateral donors tie less of their aid in larger recipient countries, i.e. those with larger populations. By using donor- 
recipient pairs as the units of analysis, we can improve on these two studies by simultaneously testing (or controlling for) independent variables measured at the level of donors, recipients, and donor-recipient pairs (including donor aid share, in the latter category).

\section{(b) Models and Data}

Data on aid tying shares were computed from the AidData portal, a database which provides development financing data at the project level ${ }^{5}$. AidData uses the CRS as a main source. The CRS reports for each project the total commitment amount, the amount of tied aid, the amount of partially tied aid and the amount of untied aid. Tied aid is defined by the DAC as development assistance where "procurement of goods and services is limited to the donor country or to a group of countries which do not include substantially all aid recipient countries." For aid to be classified as partially tied the latter must be the case, i.e. the group of eligible countries must include substantially all recipients. Finally, untied aid is defined as development assistance "for which the associated goods and services may be fully and freely procured in substantially all countries" $\left(\right.$ DAC, 2001) ${ }^{6}$. Based on these definitions we constructed and tested three alternative measures of tied aid share in estimating both models:

1. the sum of tied and partially tied aid divided by the sum of tied, partially tied and untied aid;

2. the amount of tied aid divided by the sum of tied, partially tied and untied aid;

3. the sum of tied, partially tied, and aid for which tying status was unreported, divided by the total commitment amount ${ }^{7}$.

The key predictions in section 3 concern the aid share of each donor in recipient countries (eq. 3.1) and the number of donors active in each recipient (eq. 3.5). We use a cross-sectional panel of donor-recipient observations to test the prediction from equation 3.3 that aid tying will be negatively correlated with aid share. Specifically, we estimate the following model:

$$
\sigma_{i j}=\vartheta_{0}+\vartheta_{1} S_{i j}+\vartheta_{2} L D C_{i}+\vartheta Z_{i}+\delta_{j}+v_{i j}
$$

where $\sigma_{i j}$ is the share of aid donor $j$ disburses to recipient $i$ that is tied, $S_{i j}$ is donor $j$ 's share in the total amount of aid recipient $i$ receives, and $L D C_{i}$ is a dummy variable indicating whether the recipient country is classified as a Least Developed Country. $Z_{i}$ is a vector of recipient-specific control variables. The $\delta_{j}$ are donor fixed effects and $v_{i j}$ is a well-behaved error term. 
In accordance with the model we expect a negative sign for $\vartheta_{1}$. The coefficient for $\vartheta_{2}$ should also be negative, if donors are complying with the 2001 DAC recommendation to untie aid to LDCs (see OECD, 2008). $Z_{i}$ includes the logs of population, GDP per capita, and total aid, and total aid as a share of GNI. The DAC's focus on LDCs in its aid untying campaign is premised on their heavier reliance on ODA (OECD, 2008, p. 4). Although the recommendation applies formally to LDCs, other indicators of aid dependence could be linked to the prevalence of aid untying. Although the DAC recommendation specifies LDC status only, and does not address gradations in income levels among LDCs (or non-LDCs), donors may go further and tie less aid to poorer countries, controlling for LDC status. Actual aid volume and aid share of GNI are more direct measures of aid dependence, and we expect their coefficients to be negative. Smaller countries may have less leverage in dealing with donors. If so, higher population should be associated with less aid tying.

The donor fixed effects control for any donor characteristics that increase (or decrease) a donor's tendency to tie aid in general, regardless of recipient characteristics. These characteristics may include not only degree of concern for commercial objectives, but also cultural or ideological differences, or even differences in how faithfully donors interpret the DAC's definitions when they report on aid tying status. Table 1 presents summary statistics, by donor, on aid tying (based on definition 1$)^{8}$. As shown in the table, some donors tie none (e.g. the UK) or very little (e.g. Norway) of their aid to any recipients. In fact, $46 \%$ of the variation in aid tying in our sample can be statistically (if not substantively) explained by the donor fixed effects alone. However, many donors do exhibit high variability in rates of aid tying across their recipients, including some donors with low overall rates of tying (e.g. Belgium) and others with high rates (e.g. the U.S.). This variability potentially can be explained by recipient characteristics, such as status as an LDC, but also by other factors that vary at the level of donor-recipient pairs, such as the donor's share of aid in the country.

Descriptive statistics for all variables are provided in table 2 for the main sample of 2006 observations for the year 2007. Standard errors were adjusted for donor clustering of observations. Note that all observations where the donor is a multilateral aid agency are excluded from the sample, because they exhibit no variation in the dependent variable. All multilaterals excepting the EC have no tied aid, and all of its aid is classified as partially tied ${ }^{9}$. Several small non-DAC donors are also dropped from the analysis, because they do not report aid tying status. The sample of donors thus includes 22 DAC members (all but the EC). All recipients of aid in the 
OECD's Creditor Reporting System (CRS) are included, with the exception of a small number of countries that were already classified as high income by the World Bank.

Although our aid share measure varies across donors within each recipient, the number of donors does not. We therefore test the model's prediction that more donors will be associated with higher tied aid using a cross section of 133 recipient countries for 2007. Specifically, we estimate the following equation:

$$
\sigma_{i}=\beta_{0}+\beta_{1} N_{i}+\beta_{2} L D C_{i}+\beta X_{i}+\varepsilon_{i}
$$

where $\sigma_{i}$ represents the share of aid recipient $i$ receives that is tied, $N_{i}$ is the number of donors present in recipient country $i, L D C_{i}$ is a dummy indicating whether the recipient country is classified as a Least Developed Country, and $X_{i}$ is a vector of recipient-specific controls. Summary statistics of these variables are found in table 3. Standard errors robust to possible heteroskedasticity are reported in all tests.

Several independent variables were taken from the AidData portal, including the number of donors present in a recipient country, and each donor's share of the aid given to each recipient. Total aid as a share of recipient GNI, population and GDP per capita were obtained from the World Bank's World Development Indicators. The LDC dummy is constructed based on the definition in the 2001 DAC recommendation (DAC, 2001).

\section{(c) Empirical Findings}

Results for model 4.1 are presented in table 4, for each of the three alternative definitions of tied aid. Consistent with the model's predictions, coefficients for a donor's share in the total amount of aid are significantly negative. Using either definition 1 or 2 , each percentage point increase in a donor's share in total aid is associated with a reduction of 0.4 percentage points in the share of tied aid. To illustrate, an increase in aid share from the mean value of $3 \%$ to $8 \%$ other things equal would be associated with a decline in tied aid from the mean of about $20 \%$ to $18 \%$. For definition 3, the coefficient on aid share is somewhat larger (in absolute value). The inclusion of donor fixed effects implies that this effect is identified solely from within-donor variation in aid tying and donor aid shares. I.e., any given donor ties less of its aid, on average, in countries where its share of the aid market is larger than in its other recipients.

The LDC coefficient is also significantly negative, consistent with the DAC recommendation on aid untying. Other things equal, the share of tied aid is about 6 percentage points lower 
in LDCs based on equation 1. Controlling for LDC status, differences in per capita income are unrelated to aid tying. Tied aid tends to be lower in larger countries: the coefficient on log of population is negative and marginally significant in all three equations. Tied aid is significantly lower where total aid volumes, and aid as a share of national income, are higher. These results are generally consistent with the spirit of the DAC recommendation on aid untying, namely that it is particularly important to maximize the value of aid by untying it in countries more dependent on aid.

The DAC's reports on aid tying focus on definition 1. This is also the aid untying indicator included in the Paris Declaration monitoring framework. In describing robustness of our results on aid share to changes in specification or sample, we therefore also use definition 1 , where space constraints lead us to select only one of the three indicators. First, we consider the possibility of influential observations. Figure 1 depicts the partial relationship between tied aid and aid share, based on equation 1. Visual examination suggests that a handful of high values on aid share could be influential in producing its negative and significant coefficient. Accordingly, in equation 4 we re-run equation 1, but dropping the 37 observations in which a donor's aid share exceeds one-third. The aid share coefficient remains negative and significant, and even increases in magnitude.

The majority of aid share values in the data are under $1 \%$. Arguably donors have no leverage in these cases (Munro, 2005), or if they do, there is no real increase in leverage from providing (say) $0.8 \%$ instead of $0.2 \%$. We therefore checked to ensure that our results were not sensitive to the possibly spurious variation among these small values. Specifically, we tested an alternative aid share variable in which all values greater than $0 \%$ but under $1 \%$ were set equal to $1 \%$. Results are shown in equation 5 . The coefficient and significance of the aid share variable are affected only trivially, compared to the base specification of equation 1 .

The majority of tied aid values in the panel data are equal to one of the extreme points, 0 or 1. We are unable to use a tobit estimator, because fixed-effects tobit estimates are biased. The value added of tobit estimation is relatively small in any case, according to Angrist and Pischke (2009). However, we report results in table 5, equation 1 for the smaller sample of values strictly between 0 and 1 . Aid share remains highly significant in this limited set of observations.

In equation 2 of table 5, we return to using the full sample but add Control of Corruption as a regressor. Where recipient-country procurement systems are believed to be more corrupt, donors are more likely to bypass them and use their own rules and procedures, including aid tying. This reasoning implies the coefficient on Control of Corruption should be negative. Although it is in 
fact negative in equation 2, the coefficient is very small and not significant. Results for the key aid share variable are unaffected. Similar results are obtained if we instead use the well-known Corruption Perceptions Index from Transparency International. However, corruption is associated with higher rates of aid tying in cross-sectional tests reported below.

There are potentially many more recipient-country characteristics, other than those explicitly controlled for thus far, that could affect the level of aid tying. The most effective way to correct for any omitted-variables bias in our results for the key aid share variable is simply to replace the recipient-country variables with a full set of recipient country dummies. Equation 3 reports results from this two-way fixed effects regression. The coefficient on aid share (-.36) is slightly larger in absolute value than in the base specification (-.34), and its statistical significance strengthens, from the .05 to the .01 level.

We also tested other variables that vary at the level of donor-recipient pairs, and are potentially correlated with donor aid share. These include the share of aid in the form of food assistance, and the share of aid delivered via NGOs. These variables turned out to be statistically insignificant (with t-stats well below 1.0 in absolute value), and their inclusion did not affect results on the donor share variable. For space reasons these results are not reported in the tables.

In equations 4 and 5 we report tests of the effects of costs of aid tying for donors, using donor size and income as rough proxies for costs. The value of aid in general should be reduced by more when it is tied to purchases in smaller donor countries, because the pool of qualified firms or consultants is likely to be smaller. Consultant fees (and thus tying costs) are likely to be higher in higher-income donor countries ${ }^{10}$. In equation 4 , tying costs are proxied by the $\log$ of population and log of per capita income in current US dollars (both for 2006). In equation 5 we substitute for population the log of total aid, measured in constant US dollars and averaged over the years 1995-2006. The rationale for this proxy is that the number of firms and consultants residing in the country with expertise pertinent to development assistance increases (but at a diminishing rate) with past and present aid expenditures. To test these donor-level variables we have to drop the donor fixed effects, and we instead use recipient fixed effects, and correct standard errors for recipient-clustered rather than donor-clustered observations. Aid tying is positively and significantly related to both donor size measures, as expected, in equations 4 and $5 .{ }^{11}$ Income, as predicted, is inversely (and significantly) related to the incidence of aid tying in both tests. We cannot rule out the possibility that smaller and wealthier donors tie less of their aid for other reasons, but the relationships are consistent with our theoretical framework. Donor aid share 
remains highly significant in both tests.

Amegashie et al. (2007) raise the possibility that the costs of tying aid must be balanced against losses from graft when aid is untied. Where corruption levels are high, tying aid does not necessarily reduces its development benefits. A testable implication is that the negative relationship between aid shares and aid tying should strengthen when the most corrupt recipient countries are dropped from the sample. Accordingly, we re-ran the base specification separately for the sub-samples of recipients scoring above and below the mean value on the "Control of Corruption" variable from the Worldwide Governance Indicators project (where higher scores indicate lower perceived corruption). For space reasons, table 6 reports results for the donor share coefficient, but does not report full regression results for the control variables. For comparison purposes, row 1 shows results for the base specification, i.e. the -.341 coefficient from 4, equation 1. As shown in row 2, the donor share coefficient is slightly higher in absolute value (-.371) for the 878 observations with above-average Control of Corruption ratings. Row 3 reports a somewhat smaller coefficient of -.276 for the 1124 observations with below-average Control of Corruption ratings. ${ }^{12}$ The difference between these two coefficients is not statistically significant at conventional levels, however.

In the remainder of table 6, we report similar results for two alternative years, 2005 and 2009. Most of our analyses are based on 2007 data, which was the most recent year that complete data were available when we began the study. To ensure that results for 2007 are not anomalous, we created similar datasets for 2005 and for 2009 (the most recent year currently available). As shown in rows 4 and 7 of table 6, respectively, the donor aid share coefficients for 2005 and 2009 are negative as hypothesized, but somewhat smaller in magnitude and not as highly significant as in row 1 (for 2007). Although these results for 2005 and 2009 are consistent with the central hypothesis of this study, therefore, they are not as strongly supportive as are the findings for 2007 . On the other hand, evidence on our secondary hypothesis regarding corruption is much stronger using the data from 2005 or 2009. Specifically, the donor aid share coefficients are large, negative and significant in the less-corrupt sub-sample of countries in each year. For both years - as shown in rows 5 and 8 of table 6 - there is no relationship between donor aid share and aid tying in recipients with below-average ratings on Control of Corruption. These results are consistent with theoretical predictions that aid tying may be an efficient response by donors when losses from embezzling aid funds may rival or exceed the costs from tying aid. Where corruption is less severe, and tying aid is more likely to reduce its development impact, then a higher donor aid share reflecting a more "encompassing interest" in the country's development - is inversely related to 
the rate of aid tying.

\section{(d) Endogeneity of Aid Share}

Regressions in tables 4 and 5 treat aid share as exogenous. Conceivably the negative coefficient on aid share reflects endogeneity bias. For example, suppose recipients discourage aid from donors that tie more of their aid (so their shares fall), and lobby for more aid from other donors (and their shares rise). Then, higher tied aid would be associated with lower aid shares, due to reverse causation. With a few notable exceptions (such as India), however, most recipients appear to accept whatever aid they are offered, and when they can be selective they may care more about conditionality, sector, modality, and other issues than about tying status. If donor aid shares are determined more by donor than by recipient decisions, any reverse causation would likely produce a positive bias. For example, a donor agency (under pressure from lobby groups or parliament) may increase aid to recipients where it is easier to tie aid. Nevertheless we attempt to correct for any possible endogeneity bias empirically using instrumental variables estimation.

In table 7 we treat aid share as endogenous in estimating its effects on tied aid using 2SLS. Exogenous instruments for aid share include (1) geographic distance between the capital cities of the donor and recipients, (2) a dummy for whether or not the recipient is a former colony of the donor country, and (3) share of aid from multilateral donors, including the EC. Data on distance were obtained for 1946 observations from Gleditsch (2011), and supplemented with our own research for 13 other observations belonging to Tonga and Kiribati. The colonial ties variable was the product of our own research, and is defined with respect to the final colonial power for recipients where there was more than one. Data on multilateral aid shares are from AidData.

Colonial ties have been shown in various studies to be associated with higher aid from a donor (e.g. Alesina \& Dollar, 2000). Donors also tend to focus more of their aid on countries within their geographic region, for example Japan and Australia in the East Asia and Pacific region. This likely reflects enhanced geo-political interests, as well as lower costs in providing aid (such as shorter flights for donor missions). Colonial ties and distance vary across observations both by donors and by recipients. The third instrument, share of aid from multilaterals, is a recipient-level variable. In recipients with higher shares of multilateral aid, aid shares for each bilateral donors should be lower (unless there are fewer of them present). The share of aid from multilaterals should have no direct effect on tying status of bilateral aid, although we cannot rule out the possibility that the decisions of some bilaterals may be influenced one way or the other by greater multilateral involvement in a country. For colonial ties and geographic distance, it is conceivable they could 
affect aid tying directly. If donors have more of a stake in development outcomes in recipients that are ex-colonies or geographically closer, they might not only provide more aid to them but also provide it in ways that make it more productive. However, our instruments easily pass the relevant tests of over-identification in our 2SLS tests, reported in table 7. Depending on which of the three alternative tied aid measures are used, p values for the Hansen's J test statistic range from .29 to .38 , so the null hypothesis that the excluded instruments are correctly excluded cannot be rejected.

Equation 1 in table 7 reports the first stage regression for our 2 SLS tests. ${ }^{13}$ As in tables 4 and 5, standard errors are adjusted for donor-clustered observations. Distance, colonial ties, and multilateral aid share are all significant at the .01 level. Coefficients for distance and multilateral share are negative as expected, and positive for colonial ties as expected. An F test confirms the strength of these excluded instruments: the F statistic is 6.7, significant at the .0024 level.

Equation 2 reports the second-stage results for tied aid, based on definition 1. The aid share coefficient is negative as in the OLS regressions, and is somewhat larger in absolute value. It is significant only at the .10 level however. Results for other variables, including the LDC dummy, are very similar to their OLS counterparts. Equation 3 reports second-stage results for tied aid based on definition 2 (i.e. treating partially tied aid as untied). Results on aid share are similar to those in equation 2 , but with a slightly larger coefficient (-.5 compared to -.47) and test statistic (1.88 compared to -1.73). Equation 4 is based on definition 3, which treats aid with its tying status unreported as being tied. Aid share is significant at the .05 level, with a coefficient slightly larger in absolute value (-.61 compared to -.57) than in the corresponding OLS regression in table 4 . The key finding that donors with higher aid shares tie less of their aid is thus robust to correcting for potential endogeneity of aid shares.

\section{(e) Cross Sectional Tests}

The results of model 4.2, tested for a cross-section of recipient countries, are also mostly in accordance with our theoretical predictions (see table 8). The key variable is now the number of donors, instead of a donor's share of aid, so the expected coefficient sign is now positive instead of negative. Equation 1 of table 8 reports results for definition 1 of the dependent variable. A larger number of donors is associated with a higher tied aid share; this positive relationship is significant at the .01 level. Each additional donor is associated with an increase of 1.3 percentage points in the total share of the recipient country's aid that is tied. The LDC dummy is negative and significant at the .10 level: other things equal, the tied aid share in LDCs is 10 percentage points lower 
than in other aid recipient countries. Control variables are not significant in equation 1. Equation 2 substitutes definition 2 of tied aid. The coefficient on number of donors is again positive and (even more) highly significant. The control variables are also significant in this regression, mostly with the same coefficient signs as in the panel data tests. Equation 3 shows that the positive and significant result for number of donors is also robust to using definition 3 of tied aid, although it is the only significant regressor in this test.

Equations 4 and 5 replicate equations 1 and 2, but adding two more regressors, the EC's aid share and the share of other multilateral aid. In the panel data analysis, tied aid was measured for each bilateral donor-recipient pair, so there was no reason to expect any direct effect of multilateral aid shares. In table 8, tied aid is aggregated over all donors for each recipient. The fact that EC aid is partially tied and other multilateral aid untied should thus have a direct effect on the share of tied aid in these cross-sectional tests ${ }^{14}$. The predicted sign for the EC aid share depends on whether or not partially tied aid is defined as tied. In equation 4 , based on definition 1 , we observe the expected positive (and significant) coefficient on EC aid share. Each percentage point increase in the EC aid share increases the tied aid share by slightly more than 1 percentage point. In equation 5 , based on definition 2 , we observe the expected negative (and significant) coefficient on EC aid share. The expected negative coefficient on share of aid from other multilateral donors is not observed, however, in either equation 4 or 5 . This finding suggests that bilateral donors may tie (or partially tie) a larger share of their aid when multilaterals (other than the EC) are present in force. Inclusion of these two regressors further strengthens the significance of the number of donors in equation 4 (relative to equation 1) and leaves it unaffected in equation 5 (relative to equation 2).

Additional robustness tests are reported for the cross-sectional analysis in table 9 , based on definition 1 of tied aid. In equation 1, we add the Control of Corruption indicator. Although it was insignificant in the panel data tests in table 4 , it exhibits the expected negative and significant effects on tied aid in this cross sectional regression. Higher values - meaning lower perceived government corruption - are associated with lower rates of aid tying by donors, as expected ${ }^{15}$. Results on the number of donors variable are not affected by the inclusion of the corruption indicator.

As in the panel data tests, tied aid is more sensitive to the market structure of aid when more highly corrupt countries are excluded from the sample. When the sample is split by the median value of Control of Corruption, the coefficient on number of donors is .015 (significant at .001) for 
the less corrupt sub-sample, and .009 (significant at .05) for the more corrupt sub-sample ${ }^{16}$. Again, these findings are consistent with our theoretical framework: where aid tying is less inefficient (or possibly even efficient), the strengthened incentives of donors in less-fragmented aid environments to act efficiently has more ambiguous implications for aid tying.

Some empirical studies of aid fragmentation omit donors that provide only very small amounts of aid, often representing non-project technical cooperation, such as scholarships or small grants channeled through NGOs. The rationale in omitting these "micro-aid" relationships is that they do not typically entail significant transactions costs for recipient governments. The presence of these small donors may similarly not add in any meaningful way to the competitiveness of the aid market in the country. Providing scholarships or micro-grants to NGOs does not necessarily indicate a willingness to provide larger amounts of aid to governments, so recipients may not be able to use them as leverage in negotiating with their other donors. In equation 2, therefore, we follow OECD (2009) in counting as donors only those providing more than $\$ 250,000$ in aid to the country. This change in definition reduces the average number of donors per country in the sample from 26 to 20. The coefficient on number of donors in equation 2 remains positive and highly significant, however.

Remaining regressions in table 9 go beyond model 4.2, replacing the number of donors with an aid fragmentation index, and exploring the possibility of a nonlinear relation between number of donors and the share of tied aid. Equation 3 replaces the number of donors with an index of donor fragmentation, equal to one minus the sum of squared shares of each donor's aid in the country. This index has been used in studies of aid fragmentation (e.g. Knack \& Rahman, 2007), and is based on the Herfindahl index of market concentration, a standard measure of monopoly power in the industrial organization literature. Its coefficient in equation 3 is positive and highly significant: tying of aid is more likely where aid is more fragmented across donors. As with the results above on aid shares and on the number of donors, this result is consistent with the argument that donors give lower weight to development objectives and higher weight to commercial or other donor-specific objectives of their aid programs when responsibility is more diffused.

We tested for nonlinear relationships with tied aid in the panel data (for aid shares) and in the cross sectional data (for number of donors and fragmentation indexes). One possibility is that tied aid increases monotonically with (say) number of donors, but at a diminishing rate. However, taking the log of number of donors (or aid shares, in the panel data) does not improve the empirical fit. Another possibility is that the relation is quadratic. For aid share in the panel 
data, the quadratic specification was not significant, and we conclude that the negative relationship between aid share and tied aid is at least roughly linear ${ }^{17}$. Quadratic relationships turn out to be significant in the cross-sectional data, however. In equation 4 , the number of donors and its square are both highly significant, with tied aid first increasing but eventually declining as the number of donors increases beyond 30. The explanatory power of the model $(\mathrm{R}$ square $=.78)$ improves relative to its linear counterpart in equation 4 of table $8(\mathrm{R}$ square $=.72)$. This quadratic relation is robust to excluding the micro-donors from the count of number of donors, as shown in equation 5 of table 9 . The tied aid share first increases with the number of (non-micro) donors, but above 26 it decreases.

These curvilinear relationships are not driven by a small number of extreme values: there are dozens of countries in the sample with more than 30 donors. However, it seems doubtful that the decline in (predicted values of) tied aid as the number of donors increases from, say, 30 to 35 , has anything to do with a more competitive aid market that gives recipients more leverage in negotiating with donors. It is more plausible that an increase from, say, 5 to 10 donors might increase competition, but that increase is associated with a predicted rise in the share of aid that is tied. The quadratic relationship is not predicted by our model, but nor is it predicted by the argument that concentrating aid in a country among fewer donors comes at the expense of giving them more market power.

Equation 6 in table 9 reports a significant quadratic relationship for the fragmentation index. In this case, the improvement in explanatory power is marginal $(\mathrm{R}$ square $=.73$, compared to .72 in equation 3). Moreover, the predicted maximum for tied aid is at a fragmentation index value of .98 , while all of the actual values in the sample are .92 or below. For all 133 countries in the sample, therefore, the tied aid share is predicted to increase with fragmentation - the opposite of what we would observe if more fragmentation implies less market power for donors in a country.

\section{SUMMARY AND CONCLUSION}

In this paper we tested two opposing hypotheses regarding the effect of aid fragmentation on aid tying. Results offer no support for the hypothesis that more concentrated aid confers monopoly power on donors that they exploit by tying more of their aid. Instead, we find strong evidence that lower fragmentation is associated with less aid tying. This result is predicted by a model of donor behavior based on collective action theory. In countries where aid is less fragmented across donors, the typical donor has stronger incentives to pursue development objectives rather than commercial (or other) objectives. A given donor operating in multiple recipient countries has a 
stronger incentive to pursue development objectives where it has a larger share of the total aid market in a country. Our findings are robust to alternative definitions of aid tying, and to a strong set of controls (including donor and recipient fixed effects). Moreover, instrumental variables tests in our panel data support the interpretation that higher donor aid shares reduce aid tying. In our cross-sectional tests, aid tying rises initially as the number of donors increases, but eventually begins to fall. This result - that aid tying is lower not only when there are very few but also very many donors - is not predicted by our theoretical approach, but nor is it consistent with concerns that fewer donors operating in a country implies enhanced leverage on their part to tie more aid. Moreover, in our panel data tests, higher donor aid shares are monotonically associated with lower aid tying.

Aid tying also varies inversely with the costs of aid tying (proxied empirically by donor country size and per capita income), as predicted by the model. We also find that aid to the LDCs is less likely to be tied, indicating that the DAC recommendation on aid untying to least developed countries has influenced donor behavior.

This paper adds to the sparse literature (Amegashie et al., 2007; Clay et al., 2009) on the determinants of aid tying, and to a growing body of empirical evidence on the adverse impact of fragmented aid (Anderson, 2011; Djankov et al., 2009; Knack \& Rahman, 2007). Fragmentation indicators (including donor aid shares) are only incomplete measures of the division of labor among donors, and division of labor in turn does not comprise the entire donor harmonization agenda. For example, we do not address fragmentation at the sectoral level, delegation of implementation of aid by one donor to another, or coordinating donor missions or country analytic work. Our model and empirical tests aggregate all ODA to the donor-recipient level. However, our approach could readily be extended to sector-by-sector analyses in further research. For a given donor-recipient pair, one could test the hypothesis that aid tying is lower in sectors where the donor's aid share is higher, controlling for donor and sector fixed effects.

This study is limited to the DAC donors. Although the tying status of most aid from non-DAC donors is not reported, much of it is believed to be tied (Kragelund, 2008). Non-DAC donors account for a small but growing share of all aid, so their tying practices are likely to become a more prominent issue in coming years.

Despite the limitations of our analysis, it reassuringly finds that the objective of untying more aid does not conflict with at least one part of the harmonization agenda - increasing geographic specialization of aid by donors. Results instead are consistent with the view that reducing frag- 
mentation - by increasing donors' share of aid in the countries they assist - enhances their reputational stake in producing favorable development outcomes. Reducing aid fragmentation can occur without donors (individually or collectively) imposing their own preferred geographic division of labor. The Rwandan government, for example, has taken the lead in guiding its donors toward providing support in a more limited number of sectors, based on its own views of donors' comparative advantages. International Good Practice Principles for Country-Led Division of Labor and Complementarity, issued by the DAC in 2009, endorse this approach (OECD, 2011).

\section{REFERENCES}

Acharya, A., de Lima, A. T. F., \& Moore, M. (2006). Proliferation and fragmentation: Transactions costs and the value of aid. The Journal of Development Studies, 42(1), 1-21.

Alesina, A., \& Dollar, D. (2000, March). Who gives foreign aid to whom and why? Journal of Economic Growth, 5(1), 33-63.

Amegashie, J. A., Quattara, B., \& Strobl, E. (2007). Moral hazard and the composition of transfers: Theory with an application to foreign aid (CESifo Working Paper No. 1996). The CESifo Group.

Anderson, E. (2011). Aid fragmentation and donor transaction costs (Working Paper No. 31). University of East Anglia, School of International Development.

Angrist, J. D., \& Pischke, J.-S. (2009). Mostly harmless econometrics: An empiricist's companion. Princeton: Princeton University Press.

Aryeetey, E., Osei, B., \& Quartey, P. (2003). Does tying aid make it more costly? A Ghanaian case study (Paper presented at the Workshop in Quantifying the Impact of Rich Countries' Policies on Poor Countries). Center for Global Development and Global Development Network.

Birdsall, N., Kharas, H., \& Perakis, R. (2011). Quality of official development assistance assessment: Is aid quality improving? Washington, D.C.: Brookings Institution and Center for Global Development.

Cassen, R. (1986). Does aid work? Cambridge: Cambridge University Press.

Clay, E., Geddes, M., \& Natali, L. (2009). Untying aid: Is it working? An evaluation of the implementation of the Paris Declaration and on the DAC recommendation of untying aid to LDCs. Danish Institute for International Studies.

DAC. (2001). DAC recommendation on untying ODA to the Least Developed Countries. OECD.

Djankov, S., Montalvo, J. G., \& Reynal-Querol, M. (2009). Aid with multiple personalities. 
Journal of Comparative Economics, 37, 217-229.

Easterly, W. (2002). The cartel of good intentions: The problem of bureaucracy in foreign aid. Journal of Policy Reform, 5(4), 223-250.

Easterly, W., \& Williamson, C. (2011). Rhetoric vs. reality: The best and worst of aid agency practices. World Development, 39(11), 1930-1949.

Frot, E., \& Santiso, J. (2008). Development aid and portfolio funds: trends, volatility and fragmentation (Working Paper No. 275). OECD Development Centre.

Frot, E., \& Santiso, J. (2009). Crushed aid: Fragmentation in sectoral aid (SITE Working Paper No. 6). Stockholm School of Economics.

Gibson, C. C., Andersson, K., Ostrom, E., \& Shivakumar, S. (2005). The samaritan's dilemma: The political economy of development aid. Oxford University Press.

Gleditsch, K. (2011). Distance between capital cities data. Retrieved from http://privatewww.essex.ac.uk/ ksg/index.html

Hardin, R. (1982). Collective action. Baltimore: John Hopkins University Press.

IEG. (2011). World Bank progress in harmonization and alignment in low income countries. World Bank.

Jepma, C. J. (1991). The tying of aid. Paris: OECD Development Center.

Kimura, H., Sawada, Y., \& Mori, Y. (2007). Aid proliferation and economic growth: A crosscountry analysis (RIETI Discussion Paper Series 07-E-044). Research Institute of Economy, Trade and Industry.

Knack, S., \& Rahman, A. (2007). Donor fragmentation and bureaucratic quality in aid recipients. Journal of Development Economics, 83(1), 176-197.

Knack, S., Rogers, H., \& Eubank, N. (2011). Aid quality and donor rankings. World Development, $39(11), 1907-1917$.

Kragelund, P. (2008). The return of non-dac donors to africa: New prospects for african development? Development Policy Review, 26(5), 555-584.

Martens, B., Mummert, U., Murrel, P., \& Seabright, P. (2002). The institutional economics of foreign aid. Washington, D.C.: Cambridge University Press.

Munro, L. T. (2005). Focus-Pocus? Thinking critically about whether aid organisations should do fewer things in fewer countries. Development and Change, 36(3), 425-447.

OECD. (2008). DAC recommendation on untying ODA. OECD.

OECD. (2009). 2009 OECD report on division of labour. OECD Journal on Development, 10(4), 
15.

OECD. (2011). Aid effectiveness 2005-10: Progress in implementing the Paris Declaration. OECD Publishing.

Olson, M. (1965). The logic of collective action: Public goods and the theory of groups. Cambridge: Harvard University Press.

Olson, M. (1982). The rise and decline of nations: Economic growth, stagflation and social rigidities. New Haven: Yale University Press.

Rogerson, A. (2005). Aid harmonisation and alignment: Bridging the gaps between reality and the Paris reform agenda. Development Policy Review, 23(5), 531-552.

Rowlands, D., \& Ketcheson, I. (2002). Multilateral aid coordination by the international financial institutions: An examination of canadian development assistance to sub-saharan africa. In e. Arvin B.M. (Ed.), . Westport: Praeger.

World Bank. (2003). World development report 2004: Making services work for poor people. Washington, D.C.: World Bank.

\section{NOTES}

${ }^{1}$ Effective in 2009 the recommendation was extended to cover non-LDC HIPC countries.

${ }^{2}$ In the model a donor either ties none or all of its aid in each country it assists. In the majority of actual donor-recipient pairs in the data, donors do tie either all or none of their aid. In about $40 \%$ of cases, however, donors tie more than $0 \%$ but less than $100 \%$ of their aid. The model can be readily generalized from the discrete choice case to the continuous case, to predict that the proportion of aid a donor disburses that it chooses to tie, $a_{i, T} / a_{i}$, will be lower for donors with high aid shares.

${ }^{3}$ Even if there are sizeable losses of aid to corruption, what is at issue here is only the losses that can be averted by tying aid.

${ }^{4}$ Vietnam is a recent example. Its remarkable success in economic growth and poverty reduction since the Doi Moi did not go unnoticed by aid donors. While Japan traditionally has had the largest aid share in Vietnam among bilateral donors, many others have been drawn to the country, most with marginal aid shares. 
${ }^{5}$ See www.aiddata.org

${ }^{6}$ The qualifying term "substantially" is intended to allow compliance with international sanctions on pariah countries. Although the DAC datasets we use are the best available, they do not tell the full story on aid tying. Some aid that technically meets the untied criteria may be de facto tied (Clay et al., 2009). Many donors with a high rate of untied aid (including some small donor countries) nevertheless award a high share of aid contracts within the home country. Furthermore, some donors do not comply adequately with the transparency provisions of the 2001 DAC recommendation that call for ex ante notification to the DAC of aid contracts open for bidding and ex ante reporting on contracts awarded.

${ }^{7}$ Nine donor countries did not report the tying status of some of their aid in 2007. In definition 3, we follow Easterly (2002) in treating aid with unreported tying status as tied. Such aid is disproportionately technical assistance, which is more often tied than other aid categories (DAC, 2001). Definition 3 therefore overestimates tied aid, but definitions 1 and 2 underestimate it, for the nine donors in question.

${ }^{8}$ Note that the means do not reflect donor aggregates such as those reported in Clay et al. (2009), because each recipient country is weighted equally in Table 1.

${ }^{9}$ The EC is in some respects more like a bilateral than a multilateral donor. For example, Martens, Mummert, Murrel, and Seabright (2002, p. 192) report that "national representatives in EC foreign aid decision-making committees spend a considerable part of their time exploring and pursuing contract opportunities for national suppliers". Unlike multilateral donors, it is a member of the OECD DAC.

${ }^{10}$ Admittedly, the quality of consultants may also tend to be somewhat higher in higher-income countries.

${ }^{11}$ We do not include both donor size indicators in the same test because they are correlated at .86 .

${ }^{12}$ Dividing the sample by the mean value of the corruption perceptions indicator is arbitrary, but results are very similar for the median or other alternative cutpoints.

${ }^{13}$ Estimations were performed using STATA's XTIVREG2 procedure. 
${ }^{14}$ Multilateral aid is thus not a valid instrument for aid share in the cross sectional tests. Moreover, the other instruments used in the 2SLS panel data tests, colonial tie and distance, are defined only with respect to donor-recipient pairs, and we were unable to identify any other good instruments for 2SLS tests using cross sectional data.

${ }^{15}$ Amegashie et al. (2007) find an insignificant relationship between aid tying by bilateral donors and the quality of governance in recipient countries. Although their theoretical exposition emphasizes corruption, they measure quality of governance empirically with the Freedom House indicators of civil liberties and political freedoms.

${ }^{16}$ Results not reported in tables for space reasons but available on request.

${ }^{17}$ These results are not reported in tables for space reasons but are available on request. 


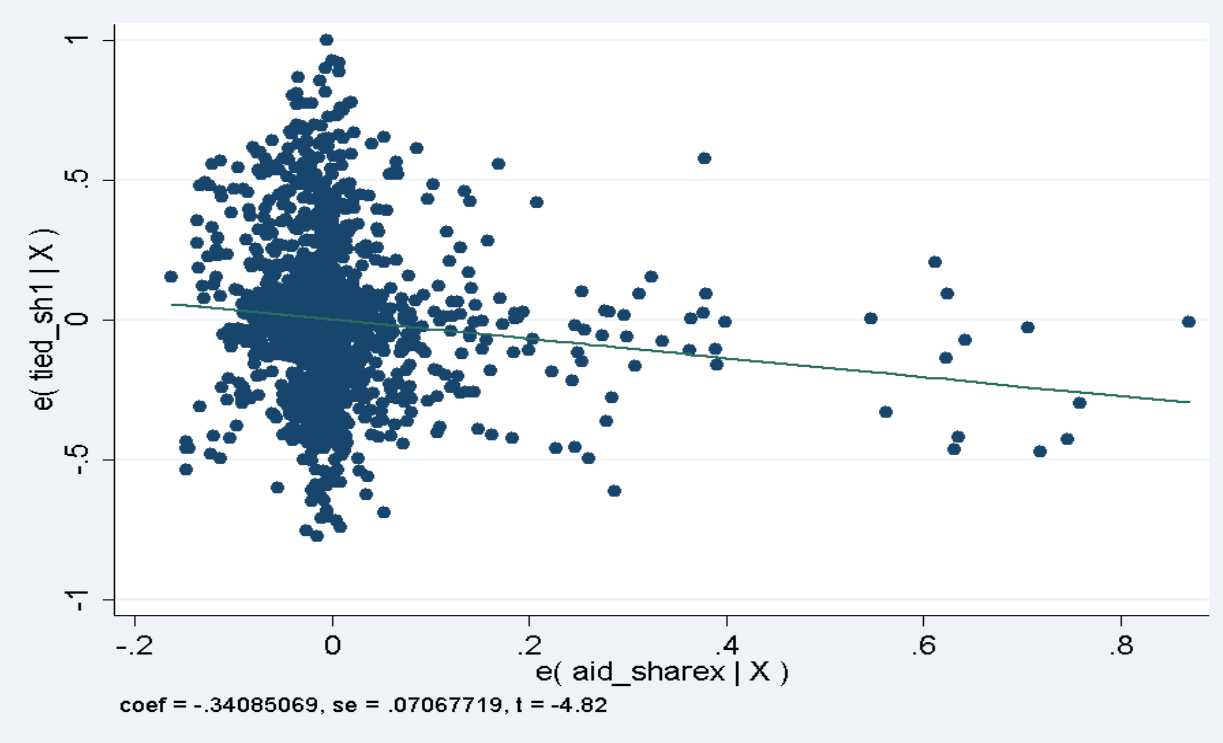

Figure 1: partial relation between aid tying and aid share (from Table 4, equation 1) 
Table 1: aid tying by donor and region

\begin{tabular}{|c|c|c|c|c|c|}
\hline donor & mean & st. dev. & min & $\overline{\max }$ & $\overline{\mathbf{N}}$ \\
\hline Australia & .00955 & .0305 & 0 & 198 & 68 \\
\hline Austria & .662 & .358 & 0 & 1 & 103 \\
\hline Belgium & .053 & .194 & 0 & .982 & 99 \\
\hline Canada & .386 & .385 & 0 & 1 & 108 \\
\hline Denmark & .106 & .267 & 0 & 1 & 50 \\
\hline Finland & .0679 & .211 & 0 & 1 & 86 \\
\hline France & .197 & .173 & 0 & .917 & 129 \\
\hline Germany & .396 & .349 & 0 & 1 & 128 \\
\hline Greece & .208 & .373 & 0 & 1 & 69 \\
\hline Ireland & 0 & 0 & 0 & 0 & 82 \\
\hline Italy & .735 & .309 & 0 & 1 & 89 \\
\hline Japan & .00914 & .0483 & 0 & .334 & 99 \\
\hline Luxembourg & 0 & 0 & 0 & 0 & 73 \\
\hline Netherlands & .269 & .385 & 0 & 1 & 87 \\
\hline New Zealand & .6 & .414 & 0 & 1 & 65 \\
\hline Norway & .00126 & .00936 & 0 & .0858 & 95 \\
\hline Portugal & .0173 & .054 & 0 & .263 & 52 \\
\hline Spain & .475 & .356 & 0 & 1 & 107 \\
\hline Sweden & 0 & 0 & 0 & 0 & 74 \\
\hline Switzerland & 0 & 0 & 0 & 0 & 109 \\
\hline United Kingdom & 0 & 0 & 0 & 0 & 106 \\
\hline United States & .456 & .342 & 0 & 1 & 128 \\
\hline East Asia and Pacific & .223 & .346 & 0 & 1 & 21 \\
\hline Europe and Central Asia & .241 & .351 & 0 & 1 & 18 \\
\hline Latin America and Caribbean & .258 & .367 & 0 & 1 & 30 \\
\hline Middle East and North Africa & .255 & .374 & 0 & 1 & 12 \\
\hline South Asia & .233 & .363 & 0 & 1 & 8 \\
\hline Sub-Saharan Africa & .189 & .32 & 0 & 1 & 47 \\
\hline
\end{tabular}


Table 2: Summary statistics panel regressions

\begin{tabular}{lcccc}
\hline \hline \multicolumn{1}{c}{ Variable } & Mean & Std. Dev. & Min. & Max. \\
\hline tied aid (1) & 0.227 & 0.35 & 0 & 1 \\
tied aid (2) & 0.208 & 0.332 & 0 & 1 \\
tied aid (3) & 0.297 & 0.384 & 0 & 1 \\
donor aid share & 0.032 & 0.087 & 0 & 1 \\
log of population & 16.139 & 1.822 & 9.183 & 20.994 \\
log of per capita income & 7.215 & 1.138 & 4.812 & 9.638 \\
LDC dummy & 0.36 & 0.48 & 0 & 1 \\
$\log$ of total recipient aid & 19.311 & 2.62 & 0 & 23.159 \\
AID/GNI & 0.077 & 0.103 & -0.001 & 0.587 \\
control of corruption & -0.539 & 0.569 & -1.588 & 1.343 \\
$\log$ of donor population & 16.800 & 1.440 & 13.066 & 19.515 \\
$\log$ of donor per capita income & 10.585 & 0.303 & 9.852 & 11.408 \\
$\log$ of total donor aid & 7.865 & 1.199 & 5.419 & 9.675 \\
$\log$ of distance & 8.726 & 0.614 & 5.79 & 9.827 \\
colonial tie dummy & 0.049 & 0.217 & 0 & 1 \\
multilateral aid share & 0.519 & 0.229 & 0.022 & 0.989 \\
\hline \hline
\end{tabular}

Table 3: Summary statistics cross sectional regressions

\begin{tabular}{lcccc}
\hline \hline \multicolumn{1}{c}{ Variable } & Mean & Std. Dev. & Min. & Max. \\
\hline tied aid (1) & 0.391 & 0.26 & 0 & 0.998 \\
tied aid (2) & 0.143 & 0.143 & 0 & 0.674 \\
tied aid (3) & 0.267 & 0.208 & 0 & 0.914 \\
No. of donors & 26.20 & 10.003 & 1 & 43 \\
No. of donors with aid $>$ 250,000 USD & 20.007 & 9.858 & 1 & 37 \\
log of population & 15.660 & 2.074 & 9.912 & 21 \\
log of per capita income & 7.143 & 1.192 & 4.559 & 9.274 \\
LDC dummy & 0.323 & 0.47 & 0 & 1 \\
log of total recipient aid & 19.716 & 1.610 & 13.215 & 22.942 \\
aid/GNI & 0.125 & 0.198 & 0.00004 & 1.664 \\
multilateral aid share (excl. EC) & 0.410 & 0.277 & 0 & 1 \\
EC aid share & 0.151 & 0.175 & 0 & 0.784 \\
Control of corruption & -0.459 & 0.568 & -1.368 & 1.349 \\
fragmentation index & 0.709 & 0.210 & 0 & 0.9203 \\
\hline \hline
\end{tabular}




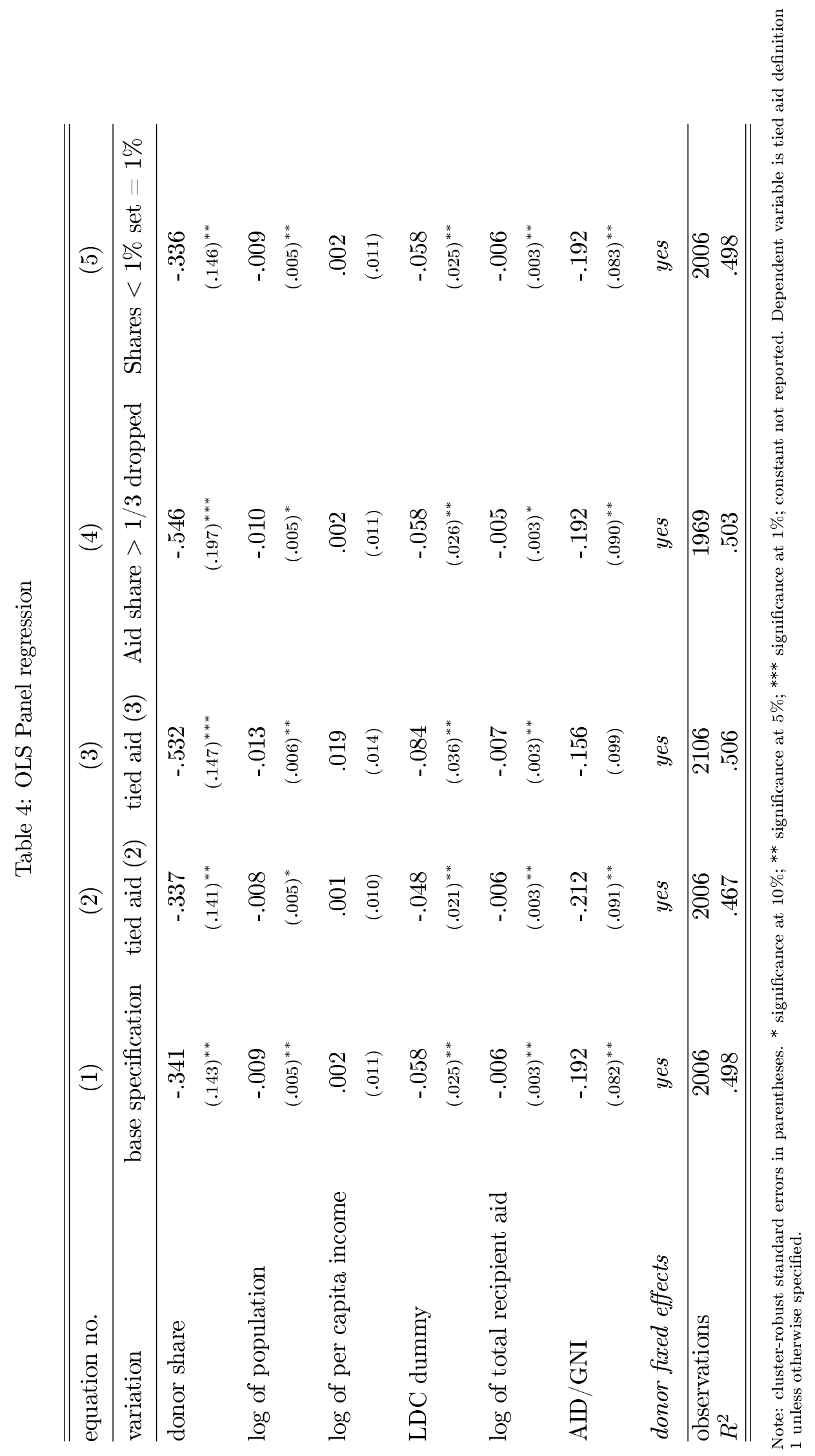




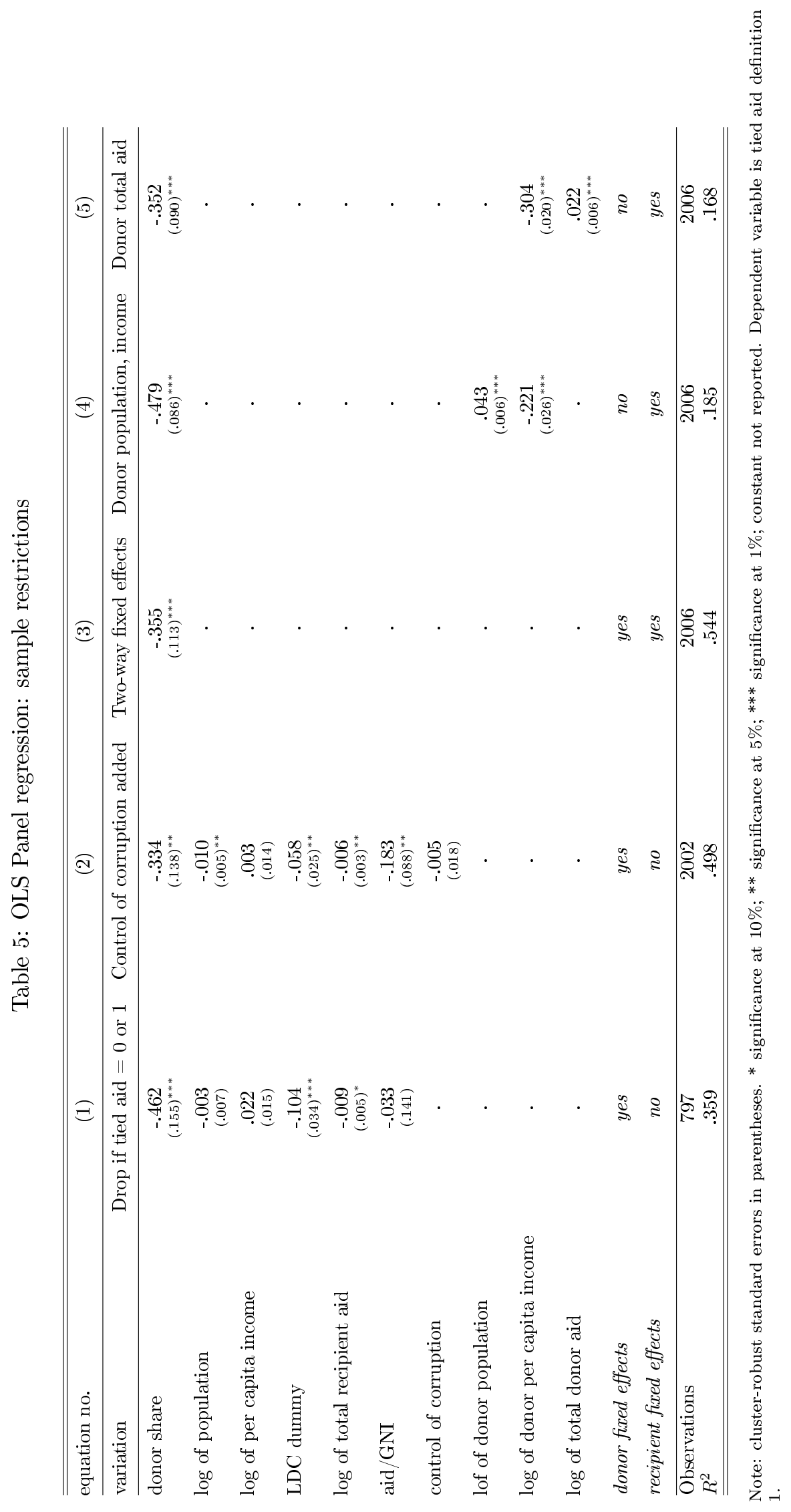


Table 6: Low vs. high corruption

\begin{tabular}{|c|c|c|c|}
\hline $\begin{array}{l}\text { sample } \\
\mathbf{2 0 0 7}\end{array}$ & donor aid share & $\overline{\mathrm{N}}$ & 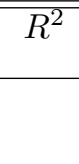 \\
\hline All & $\begin{array}{l}-0.341 \\
(.143)^{* *}\end{array}$ & 2006 & 0.50 \\
\hline Low corruption & $\begin{array}{l}-0.392 \\
(.197)^{*}\end{array}$ & 989 & 0.53 \\
\hline High corruption & $\begin{array}{l}-0.247 \\
(.114)^{* *}\end{array}$ & 1017 & 0.48 \\
\hline 2005 & & & \\
\hline All & $\begin{array}{l}-0.303 \\
(.155)^{*}\end{array}$ & 2057 & 0.56 \\
\hline Low corruption & $\begin{array}{l}-0.428 \\
(.208)^{* *}\end{array}$ & 1016 & 0.54 \\
\hline High corruption & $\begin{array}{c}-0.048 \\
(.080)\end{array}$ & 1041 & 0.56 \\
\hline 2009 & & & \\
\hline All & $\begin{array}{c}-0.186 \\
(.10)^{*}\end{array}$ & 2163 & 0.49 \\
\hline Low corruption & $\begin{array}{l}-0.354 \\
(.186)^{*}\end{array}$ & 1085 & 0.48 \\
\hline High corruption & $\begin{array}{c}0.046 \\
(.154)\end{array}$ & 1078 & 0.51 \\
\hline
\end{tabular}

Note: Dependent variable is tied aid share (definition 1). Standard errors (adjusted for clustering at donor level) are in parentheses. A* $*^{* *}$ and $* * *$ respectively indicate significance at $.10, .05$ and .01 levels for two-tailed tests. Control variables include log of population, log of per capita income, an LDC dummy, log of total recipient aid and aid/GNI. Complete regression results are available from authors on request. "Low" and "high" corruption sub-samples are defined by the sample median value of the "Control of Corruption" indicator for the relevant year. 
Table 7: 2SLS Panel regression

\begin{tabular}{|c|c|c|c|c|}
\hline equation no. & (1) & $(2)$ & $(3)$ & $(4)$ \\
\hline dependent variable & first stage & Tied aid (1) & Tied aid (2) & Tied aid (3) \\
\hline \multirow{2}{*}{ donor aid share } & . & -.473 & -.446 & -.531 \\
\hline & & $(.249)^{*}$ & $(.244)^{*}$ & $(.277)^{*}$ \\
\hline \multirow[t]{2}{*}{$\log$ of distance } & -.024 & . & . & . \\
\hline & $(.007)^{* * *}$ & & & \\
\hline \multirow{2}{*}{ colonial tie } & .122 & . & . & . \\
\hline & $(.037)^{* * *}$ & & & \\
\hline \multirow[t]{2}{*}{ multilateral aid share } & -.077 & . & . & . \\
\hline & $(.021)^{* * *}$ & & & \\
\hline \multirow[t]{2}{*}{$\log$ of population } & -.002 & -.010 & -.008 & -.012 \\
\hline & $(.002)$ & $(.005)^{* *}$ & $(.005)^{*}$ & $(.006)^{* *}$ \\
\hline \multirow[t]{2}{*}{$\log$ of per capita income } & .005 & .003 & .002 & .020 \\
\hline & $(.003)^{*}$ & $(.010)$ & $(.009)$ & $(.013)$ \\
\hline \multirow[t]{2}{*}{ LDC dummy } & .004 & -.057 & -.048 & -.083 \\
\hline & $(.010)$ & $(.025)^{* *}$ & $(.021)^{* *}$ & $(.035)^{* *}$ \\
\hline \multirow[t]{2}{*}{$\log$ of total recipient aid } & -.0004 & -.006 & -.006 & -.007 \\
\hline & $(.0008)$ & $(.003)^{* *}$ & $(.003)^{* *}$ & $(.003)^{* * *}$ \\
\hline \multirow[t]{2}{*}{$\mathrm{AID} / \mathrm{GNI}$} & .035 & -.182 & -.204 & -.154 \\
\hline & $(.044)$ & $(.073)^{* *}$ & $(.079)^{* * *}$ & $(.088)^{*}$ \\
\hline donor fixed effects & yes & yes & yes & yes \\
\hline No. observations & 2006 & 2006 & 2006 & 2104 \\
\hline F test of excl. instr. & 7.13 & . & . & . \\
\hline$F$ test $p$ value & 0.0018 & . & . & . \\
\hline$R^{2}$ & .182 & .049 & .049 & .098 \\
\hline Overid test & . & 0.76 & 1.181 & 0.901 \\
\hline
\end{tabular}

Note: cluster-robust standard errors in parentheses. $*$ significance at $10 \% ; * *$ significance at $5 \%$; *** significance at $1 \%$; constant not reported. Dependent variable is donor aid share in equation 1 , and tied aid (definitions $1-3$ respectively) in equations $2-4$. 
Table 8: cross sectional regression

\begin{tabular}{|c|c|c|c|c|c|}
\hline equation no. & $(1)$ & $(2)$ & $(3)$ & $(4)$ & $(5)$ \\
\hline variation & base specification & Tied aid (2) & Tied aid (3) & Multilateral share added & Tied aid (2) \\
\hline \multirow[t]{2}{*}{ No. of Donors } & .013 & .009 & .008 & .014 & .009 \\
\hline & $(.003)^{* * *}$ & $(.002)^{* * *}$ & $(.003)^{* * *}$ & $(.002)^{* * *}$ & $(.001)^{* * *}$ \\
\hline \multirow[t]{2}{*}{$\log$ of population } & -.035 & .027 & -.023 & .010 & .021 \\
\hline & $(.023)$ & $(.014)^{*}$ & $(.022)$ & $(.018)$ & $(.015)$ \\
\hline \multirow[t]{2}{*}{ Log of per capita income } & .026 & .033 & -.001 & .050 & .029 \\
\hline & $(.031)$ & $(.016)^{* *}$ & $(.024)$ & $(.020)^{* *}$ & $(.016)^{*}$ \\
\hline \multirow[t]{2}{*}{ LDC dummy } & -.104 & -.099 & -.064 & -.093 & -.101 \\
\hline & $(.058)^{*}$ & $(.026)^{* * *}$ & $(.042)$ & $(.034)^{* * *}$ & $(.026)^{* * *}$ \\
\hline \multirow[t]{2}{*}{$\log$ of total recipient aid } & -.036 & -.057 & -.052 & -.056 & -.054 \\
\hline & $(.033)$ & $(.022)^{* * *}$ & $(.034)$ & $(.025)^{* *}$ & $(.022)^{* *}$ \\
\hline \multirow[t]{2}{*}{ Aid/GNI } & -.118 & .125 & -.071 & .114 & .092 \\
\hline & $(.147)$ & $(.049)^{* *}$ & $(.086)$ & $(.062)^{*}$ & $(.053)^{*}$ \\
\hline \multirow[t]{2}{*}{ multilateral aid share (excl. EC) } & . & . & . & .153 & -.027 \\
\hline & & & & $(.077)^{* *}$ & $(.062)$ \\
\hline \multirow[t]{2}{*}{ EC aid share } & . & . & . & 1.251 & -.176 \\
\hline & & & & $(.060)^{* * *}$ & $(.049)^{* * *}$ \\
\hline \multirow[t]{2}{*}{ constant } & 1.183 & .389 & 1.490 & .393 & .494 \\
\hline & $(.472)^{* *}$ & $(.227)^{*}$ & $(.422)^{* * *}$ & $(.290)$ & $(.236)^{* *}$ \\
\hline No. of observations & 133 & 133 & 133 & 133 & 133 \\
\hline$R^{2}$ & .166 & .319 & .172 & .719 & .356 \\
\hline
\end{tabular}

Note: robust standard errors in parentheses. ${ }^{*}$ significance at $10 \%$; $* *$ significance at $5 \%$; ${ }^{* *}$ significance at $1 \%$.

Dependent variable is Tied aid definition 1, unless otherwise specified. 


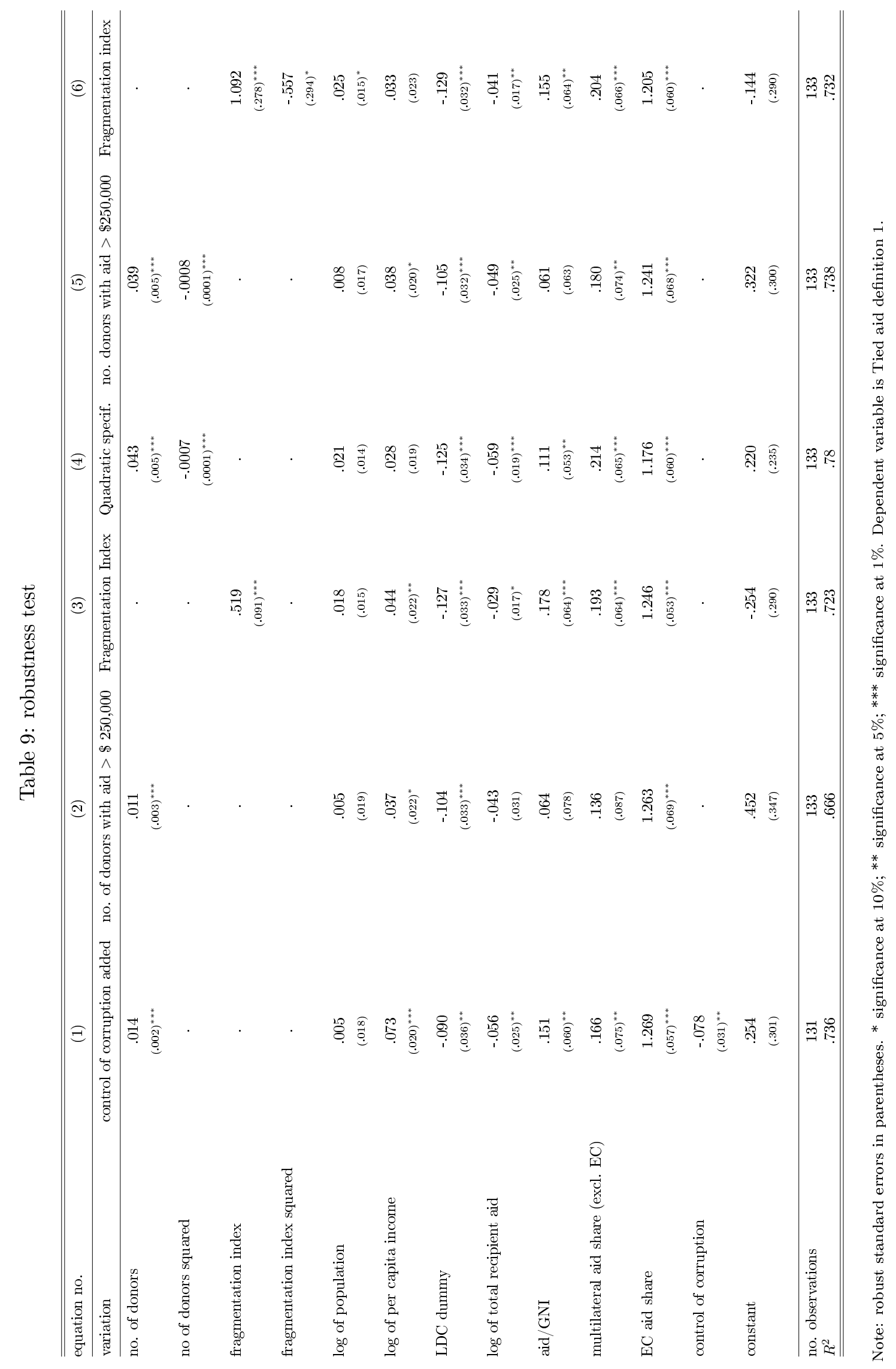

